\title{
Does Spanish instruction for emergency medicine resident physicians improve patient satisfaction in the emergency department and adherence to medical recommendations?
}

\author{
This article was published in the following Dove Press journal: \\ Advances in Medical Education and Practice \\ 5 August 2016 \\ Number of times this article has been viewed
}

\author{
LR Stoneking' \\ AL Waterbrook' \\ J Garst Orozco ${ }^{2}$ \\ D Johnston' \\ A Bellafiore' \\ C Davies ${ }^{3}$ \\ T Nuño' \\ J Fatás-Cabeza ${ }^{4}$ \\ O Beita ${ }^{5}$ \\ $\mathrm{V} \mathrm{Ng}{ }^{\prime}$ \\ KH Grall ${ }^{6}$ \\ W Adamas-Rappaport ${ }^{7}$ \\ 'Department of Emergency Medicine, \\ University of Arizona, Tucson, AZ, \\ ${ }^{2}$ Department of Emergency Medicine, \\ Sinai Health System, Chicago, IL, \\ ${ }^{3}$ Department of Emergency Medicine, \\ Maricopa Medical Center, Phoenix, \\ AZ, ${ }^{4}$ Department of Spanish and \\ Portuguese, University of Arizona, \\ Tucson, AZ, ${ }^{5}$ Department of Family \\ and Community Medicine, University \\ of Arizona, Tucson, AZ, ${ }^{6}$ Department \\ of Emergency Medicine, Regions \\ Hospital, St Paul, MN, ${ }^{7}$ Department of \\ Surgery, University of Arizona, Tucson, \\ AZ, USA
}

Correspondence: Lisa R Stoneking Department of Emergency Medicine, University of Arizona, I50I N Campbell Ave, Tucson, AZ 85724, USA

Tel +l 5206265582

Email Istoneking@aemrc.arizona.edu
Background: After emergency department (ED) discharge, Spanish-speaking patients with limited English proficiency are less likely than English-proficient patients to be adherent to medical recommendations and are more likely to be dissatisfied with their visit.

Objectives: To determine if integrating a longitudinal medical Spanish and cultural competency curriculum into emergency medicine residency didactics improves patient satisfaction and adherence to medical recommendations in Spanish-speaking patients with limited English proficiency. Methods: Our ED has two Emergency Medicine Residency Programs, University Campus (UC) and South Campus (SC). SC program incorporates a medical Spanish and cultural competency curriculum into their didactics. Real-time Spanish surveys were collected at SC ED on patients who self-identified as primarily Spanish-speaking during registration and who were treated by resident physicians from both residency programs. Surveys assessed whether the treating resident physician communicated in the patient's native Spanish language. Follow-up phone calls assessed patient satisfaction and adherence to discharge instructions.

Results: Sixty-three patients self-identified as primarily Spanish-speaking from August 2014 to July 2015 and were initially included in this pilot study. Complete outcome data were available for 55 patients. Overall, resident physicians spoke Spanish 58\% of the time. SC resident physicians spoke Spanish with $66 \%$ of the patients versus $45 \%$ for UC resident physicians. Patients rated resident physician Spanish ability as very good in $13 \%$ of encounters $-17 \%$ for $\mathrm{SC}$ versus $5 \%$ for UC. Patient satisfaction with their ED visit was rated as very good in $35 \%$ of encounters $-40 \%$ for SC resident physicians versus $25 \%$ for UC resident physicians. Of the 13 patients for whom Spanish was the language used during the medical encounter who followed medical recommendations, ten $(77 \%)$ of these encounters were with SC resident physicians and three $(23 \%)$ encounters were with UC resident physicians.

Conclusion: Preliminary data suggest that incorporating Spanish language and cultural competency into residency training has an overall beneficial effect on patient satisfaction and adherence to medical recommendations in Spanish-speaking patients with limited English proficiency.

Keywords: medical Spanish, medical education, patient satisfaction, adherence, emergency department, limited English proficiency (LEP)

\section{Introduction}

According to a 2013 census report, the number of people speaking a language other than English climbed 158\% in the past 2 decades. ${ }^{1}$ The United States Department of Commerce Economics and Statistics Administration filed a report on "Language 
Use in the United States: 2007", which showed that out of 281 million people 5 years and older in the US, $20 \%$ reported speaking a language other than English at home. Out of those 55.4 million individuals, 62\% spoke Spanish. ${ }^{2}$ In Arizona specifically, $27 \%$ of the 6 million citizens speak a language other than English at home. Spanish-speaking patients with limited English proficiency (LEP) are seen frequently in the University of Arizona Emergency Departments (EDs) in Tucson, AZ, USA, due to the extensive Latino and Hispanic heritage in the state and the proximity to the US-Mexico border.

Language, culture, and literacy are among the barriers that hinder effective communication in the health care setting. According to the Agency for Healthcare Research and Quality, approximately 9\% of the US population is at risk of an adverse event in the health care setting because of language barriers. ${ }^{3}$ Multiple studies have looked at the disparities between language and health care. ${ }^{4}$ In the ED, accurate communication of discharge instructions between physician and patient is very important. A study performed at the Kern Medical Center examined communication of discharge instructions in the setting of a growing Hispanic population and lack of bilingual attendings or professional interpreters. ${ }^{5}$ This study found that Spanish-speaking patients scored lower on all areas of understanding on the questionnaire than English-speaking patients and only correctly identified $59 \%$ of their discharge planning and diagnosis versus $82.9 \%$ for English-speaking patients, demonstrating how much language discrepancy can impact care. Another study looked at improvement in clinical care for patients with LEP when using a professional interpreter. This systematic literature review examined clinical results and patient satisfaction, finding improvement in all areas of care when using a professional interpreter and showing superior clinical outcomes and patient satisfaction. ${ }^{6}$ These studies demonstrate the necessity of effective communication between provider and patient when providing clinical care for patients with LEP.

According to the National Council on Interpreting in Health Care, the definition of a qualified interpreter is "an individual who has been assessed for professional skills, demonstrates a high level of proficiency in at least two languages and has the appropriate training and experience to interpret with skill and accuracy while adhering to the National Code of Ethics and Standards of Practice published by the National Council on Interpreting in Health Care." "7 There are now two national organizations (The Certification Commission for Healthcare Interpreters, http://www.cchicertification. org and The National Board of Certification for Medical
Interpreters, http://www.certifiedmedicalinterpreters.org) offering certification to health care interpreters whose mission it is to develop and direct comprehensive credentialing programs for health care interpreters. This is a crucial step toward the professionalization of this emerging field. The provision of services to people with LEP is also regulated by a number of federal laws and policy recommendations, including the following: ${ }^{8}$

- Title VI of the Civil Rights Act of 1964,

- Health and Human Services Policy Guidance on the Prohibition against National Origin Discrimination as it Affects Persons with Limited English Proficiency,

- Department of Justice Guidance to Federal Financial Assistance Recipients Regarding Title VI Prohibition against National Origin Discrimination Affecting Limited English-Proficient Persons,

- Culturally and Linguistically Appropriate Services Standards for Health Care,

- Executive Order 13166,

- Strategic Plan to Improve Access to HHS Programs and Activities by Limited English Proficiency Persons.

The development of regulations regarding the provision of language access and professional standards for the qualification of interpreters highlights the importance of ensuring that all patients receive the most accurate information during their stay. Taking necessary steps to guarantee accuracy when providing services to patients with LEP is crucial.

Our academic ED has two distinct emergency medicine residency programs, University Campus (UC) and South Campus (SC). One unique feature of the SC residency program is a longitudinal medical Spanish and cultural competency curriculum, which is integrated into biweekly didactics as a part of the emergency medicine residents' education. One of the goals of this curriculum is for a resident physician to acquire certification as a Dual Role Interpreter (a provider with linguistic competence in English and Spanish) in the medical setting. Our objective was to determine if integrating a biweekly medical Spanish and cultural competency curriculum into regular didactics would improve patient satisfaction and adherence to medical recommendations in Spanish-speaking patients with LEP presenting to our academic ED. We hypothesized that this curriculum would increase the number of patient encounters in which our residents would speak Spanish, thereby increasing patient satisfaction and adherence to medical recommendations in our patient population with LEP. Given the large Hispanic population that present to our ED, we felt this language 
obstacle was paramount to address. Second, we aimed to raise cultural awareness and competency in our residents in order to increase their professional preparedness and comfort level in this setting.

\section{Methods}

This study was performed at an urban, academic hospital system with two EDs and two categorical emergency medicine residency programs (UC and SC) in the US. The primary study site (SC ED) treats $\sim 45,000$ patients a year. UC and $\mathrm{SC}$ have weekly didactic educational conferences from $7 \mathrm{am}$ to $12 \mathrm{pm}$ on Tuesdays and Wednesdays, respectively. Conferences have required attendance and resident physicians are rarely scheduled to work during their allotted conference time. Thus, $\mathrm{SC}$ resident physicians are responsible for staffing both EDs on Tuesdays and UC resident physicians are responsible for staffing both EDs on Wednesdays. The SC program incorporates medical Spanish and cultural competency into its curriculum every other week. The curriculum is chief complaint based and divided into two proficiency levels, basic and advanced. An instructor from the department of Spanish and Portuguese teaches the basic group with a focus on grammar, vocabulary, and common phrases related to the chief complaint. Two clinicians fluent in Spanish teach the advanced group with a focus on clinical scenarios and role-play with partners. Class materials and resources are uploaded weekly to a Dropbox ${ }^{\mathrm{TM}}$ (Dropbox, Inc., San Francisco, CA, USA) account for residents to use as time allows. To supplement their learning, resident physicians were also given access to Canopy, a self-paced, web-based tool that uses videos and tutorials, broken down into three levels of medical Spanish, to guide the learner with the objective of obtaining advanced-intermediate conversation skills in medical Spanish. Participants undergo proficiency assessment by the Spanish instructor every 6 months to advance levels.

This was a cross-sectional, convenience sample of patients seen in the SC ED. On Tuesdays (UC resident conference day, SC resident staffing) and Wednesdays (SC resident conference day, $\mathrm{UC}$ resident staffing) between 8 am and $4 \mathrm{pm}$, patients who self-identified as primarily Spanishspeaking in our electronic health record during registration were asked to complete a real-time survey regarding their visit (Figure 1). Surveys identified the treating resident physicians and assessed whether they communicated in the patient's native Spanish language or used interpreter phones. Our residency curriculum requires trainees to continue to use translator phones until they are certified as a Dual Role Interpreter. Follow-up phone calls were performed to assess patient satisfaction and adherence to discharge instructions $\sim 1$ week later. For these two after-visit questions, a resident

Thank you for filling-out this survey. The University of Arizona Hospitals play an important role in educating new physicians. As part of our program in Emergency Medicine at South Campus, our doctors-in-training participate in a Medical Spanish Curriculum. We hope to make them better able to meet the language needs of our patients. We would like to learn how we are doing.

1. Did the resident-doctor speak Spanish with you?
2. Did the resident-doctor use a translator phone to communicate with you?
3. Did the nurse speak Spanish with you?
4. Did the supervising doctor speak Spanish with you?

8. Can we contact you to follow-up on whether you were able to fill any prescriptions and see your regular doctor?

Thank you for your help

Department of Emergency Medicine

University of Arizona

Resident Name:

Resident Year:

Program: UC SC

Date of encounter:

Attending Name:

Patient preferred language: English_Spanish

Figure I Survey translated into English.

Abbreviations: SC, South Campus residency; UC, University Campus residency. 
Table I Self-identified Spanish-speaking patients treated and Spanish language use

\begin{tabular}{llll}
\hline LEP patients & $\begin{array}{l}\text { Spanish } \\
\text { speakers (\%) }\end{array}$ & $\begin{array}{l}\text { Translator } \\
\text { phone (\%) }\end{array}$ & Unknown* (\%) \\
\hline $\begin{array}{l}\text { Overall }(\mathrm{N}=55) \\
\text { SC physicians }\end{array}$ & $32(58)$ & $8(15)$ & $15(27)$ \\
$(\mathrm{n}=35)$ & $23(66)$ & $2(6)$ & $10(28)$ \\
$\begin{array}{l}\text { UC physicians } \\
(\mathrm{n}=20)\end{array}$ & $9(45)$ & $6(30)$ & $5(25)$ \\
\hline
\end{tabular}

Note: *Family members or combination of information gathering.

Abbreviations: SC, South Campus residency; UC, University Campus residency; LEP, limited English proficiency.

physician or medical student, all proficient in Spanish and English, called the patient at the listed home phone number.

Subject participation was completely voluntary and patients were informed that participation would not affect their care. Surveys were administered after care was provided and patient status was changed to "discharge" or "transfer" on the electronic medical record tracking board. The study was granted exemption by our institutional review board as a quality improvement study.

Data are presented as percentages along with $95 \%$ confidence intervals calculated using the Jeffreys method. ${ }^{9}$ No formal statistical testing or formal power analysis was performed prior to initiating this quality improvement pilot study.

\section{Results}

Sixty-three patients self-identified as primarily Spanishspeaking and were initially included. Eight patients had missing outcome data and were excluded, leaving a sample size of 55 for our study. Overall, resident physicians spoke Spanish 58\% (32/55 patients; 95\% confidence interval $45.0-70.5$ ) of the time and used translator phones in $15 \%$ $(8 / 55 ; 95 \%$ confidence interval $7.1-25.6)$ of the encounters. The language used in the remaining $27 \%$ of the encounters is unknown - family members or a combination of information gathering. SC resident physicians spoke Spanish with $66 \%(23 / 35)$ of their patients versus $45 \%$ (9/20) for UC resident physicians. SC resident physicians used translator phones in $6 \%(2 / 35)$ of encounters while UC resident physicians used them in 30\% (6/20) of encounters (Table 1). Our survey also collected data on patient perception of resident physician Spanish-speaking ability. Patients rated resident physician Spanish as very good in 13\% of all encounters, with $17 \%$ for SC versus $5 \%$ for UC. Patient satisfaction with their ED visit was rated as very good in $40 \%$ of encounters with SC and $25 \%$ of encounters with $\mathrm{UC}$ resident physicians.
Table 2 Outcome of self-identified Spanish-speaking patients

\begin{tabular}{llll}
\hline $\begin{array}{l}\text { Communication } \\
\text { method }\end{array}$ & $\begin{array}{l}\text { Followed medical } \\
\text { recommendations* } \\
(\%)\end{array}$ & $\begin{array}{l}\text { Admitted or Excluded** } \\
\text { transferred } \\
(\%)\end{array}$ & (\%) \\
\hline $\begin{array}{l}\text { Spanish speakers } \\
(\mathrm{n}=32)\end{array}$ & $13(4 \mathrm{I})$ & $8(25)$ & $\mathrm{II}(34)$ \\
$\quad \mathrm{SC}$ & $10(77)$ & & \\
$\quad$ UC & $3(77)$ & $4(50)$ & $4(50)$ \\
$\begin{array}{l}\text { Translator phone } \\
(\mathrm{n}=8)\end{array}$ & 0 & $6(40)$ & $3(20)$ \\
Unknown (n=15) & $6(40)$ & &
\end{tabular}

Notes: *Filling a prescription or following-up with their primary care physician. **Unable to be reached or declined to speak with team.

Abbreviations: SC, South Campus residency; UC, University Campus residency.

Of the 32 total patient encounters in which the resident physicians spoke Spanish directly with the patient, 13 patients followed medical recommendations (either filling a prescription or following-up with their primary care physician), eight patients were admitted or transferred to another facility, and eleven patients were lost to follow-up (unable to be reached or declined to speak with our team). Of these 13 who followed medical recommendations, ten encounters were with SC resident physicians (77\%) and three encounters were with UC resident physicians (23\%). Of the eight patients encounters with whom we communicated via translator phones, four were admitted to the hospital or transferred to another facility and four were lost to follow-up. Of the 15 patients who reported that we did not communicate with them in Spanish, either verbally or with a translator phone, six followed medical recommendations, six were admitted to the hospital or transferred to another facility, and three were lost to follow-up (Table 2).

\section{Discussion}

This is the first pilot study at our institution's ED assessing the impact of a medical Spanish and cultural competency curriculum on patient satisfaction and adherence to medical recommendations. Centers for Medicare \& Medicaid Services require that all federally funded health care institutions provide trained interpreters for people with LEP, stating that "failure to provide language services can lead to serious medical errors and even liability for malpractice".${ }^{10}$ Our institution currently uses translator phones, which can be fraught with problems. They may be less efficient, taking a significant amount of more time to perform a thorough history and physical examination. The connection can be of poor quality and often impossible to use if the patient is hard of hearing. They can also be viewed as impersonal and make it more difficult to develop good rapport with the patient. And in the case of a trauma or critically ill patient, the translator phone is potentially useless if the patient is unable to hold it. 
Language barriers are an important detriment to quality health care. ${ }^{11-16}$ In an emergency situation, when timing is most critical, patients with LEP may be at greater risk of serious medical errors due to communication problems. After ED discharge, Spanish-speaking patients with LEP are less likely than their English-speaking counterparts to understand their diagnosis, to be prescribed medications or follow-up care, and are more likely to miss appointments and skip prescriptions. ${ }^{17}$ Spanish-speaking patients with LEP also express dissatisfaction with medical staff listening skills, getting questions answered, receiving explanations about medications, procedures or test results, and receiving reassurance and support from their medical providers. ${ }^{15}$ The use of professional interpreters is associated with improved clinical care and raises the quality of clinical care for patients with LEP to a level that approaches or equals the level of care received by patients without language barriers. ${ }^{6}$

While our program goal was to train providers capable of performing history and physical exams proficiently in English and Spanish, we did aim to have our resident physicians become sufficiently proficient in medical Spanish to ultimately acquire certification as Dual Role Interpreters during their residency training. To prepare a cadre of employees that would meet the qualifications to become certified as Spanish medical interpreters, our bilingual providers with intermediate or high levels of proficiency in Spanish were selected to participate in an Dual Role Interpreter course (16 hours over 2 consecutive days) taught by a professor and certified medical interpreter from the UA Department of Spanish and Portuguese. Upon completion of this training, these bilingual employees were made available to communicate or assist in communicating with patients with LEP whose primary language is Spanish and who are seen in the ED. However, our program goal was to train providers capable of performing history and physical exams proficiently in English and Spanish, and not necessarily to provide interpretation for other members of the medical team. Over the last 3 years, the SC Emergency Medicine residency has trained nine resident physicians, two nurses, and one medic as Dual Role Interpreters. These members of the medical team had to "pass" the Dual Role Interpreter training program in order to be certified, meaning they had to obtain the necessary competence in Spanish as determined by the Spanish instructor and trained interpreter.

Besides the aforementioned advantages, this unique curriculum is a strong recruitment tool for our residency program. Residency training is busy and having a medical Spanish curriculum integrated into mandatory didactics is appealing to applicants. Becoming proficient in another language is time-consuming, but having lessons incorporated into classroom learning makes it more easily attainable. Additionally, resident physicians feel that becoming proficient in medical Spanish improves their efficiency in the ED as they save time by not having to use interpreter phones and that it makes them more marketable when graduating from residency.

\section{Limitations}

This was a single-center study performed at an urban, academic ED that sees $\sim 45,000$ patients a year. Therefore, it may not be generalizable to other institutions. However, this curriculum is feasible to implement and assess at any residency program in any specialty of medicine.

Although Tucson's population is $41 \%$ Hispanic and South Tucson's population is $78.5 \%$ Hispanic, the percent of patients who presented to our ED reporting a primary language of Spanish was found to be only $11.52 \%$ during our study period. Our institution treats a predominantly underserved Hispanic population, in addition to an unspecified percentage of undocumented individuals (mostly Spanish speakers). Thus, this number was felt to be extremely low and secondary to an error in our electronic health record system in which the primary language automatically defaults to English unless manually changed by the registration personnel. Given that we expected a higher enrollment rate, our sample size was not large enough to detect a significant difference. However, enrollment is ongoing for this quality improvement study and will hopefully soon reach statistical significance. We are also discussing with our institution's health record personnel a requirement to manually enter each patient's primary language during registration.

Surveys were conducted on Tuesdays and Wednesdays to control for providers who participate in the medical Spanish curriculum. Therefore, most surveys conducted on Tuesdays were from SC residents and those conducted on Wednesdays were from UC residents. However, there could be some mixture of the two programs from $1 \mathrm{pm}$ to $4 \mathrm{pm}$, the time following weekly didactics. Our goal was to assess whether our curriculum impacted patient satisfaction and adherence to medical recommendations by increasing the number of Spanish-speaking providers and integrating cultural competency into our curriculum. However, after removing patients without complete information and patients who were lost to follow-up or admitted or transferred to another facility, we were left with only 13 patients to compare. Although ten of these 13 encounters were with SC residents compared to three 
Table 3 Self-reported Spanish language fluency in ERAS ${ }^{\circledR}$ prior to beginning residency for all UC and SC physicians for academic year 2014-2015

\begin{tabular}{|c|c|c|c|c|c|c|}
\hline \multirow{2}{*}{$\begin{array}{l}\text { Residency Program and } \\
\text { Postgraduate year }\end{array}$} & \multicolumn{6}{|c|}{ Spanish language fluency** } \\
\hline & None & Basic & Fair & Good & Advanced & Native/functionally native \\
\hline UC PGYI $(n=18)$ & 9 & 2 & 1 & 1 & 4 & 1 \\
\hline SC PGYI $(n=6)$ & 2 & 2 & I & 0 & I & 0 \\
\hline UC PGY2 (n=18) & 2 & 11 & I & 2 & 2 & 0 \\
\hline SC PGY2 (n=6) & I & 1 & 0 & 2 & 2 & 0 \\
\hline UC PGY3 $(n=18)$ & 9 & 2 & 0 & 2 & 3 & 2 \\
\hline SC PGY3 $(n=6)$ & 3 & 0 & 0 & 1 & I & 1 \\
\hline UC PGY4* $(n=3)$ & I & 1 & I & 0 & 0 & 0 \\
\hline UC PGY5* $(n=2)$ & 2 & 0 & 0 & 0 & 0 & 0 \\
\hline
\end{tabular}

Notes: *5-year EM/pediatrics combined residents. **Basic: I speak the language imperfectly and only to a limited degree and in limited situations. I have difficulty in or understanding extended conversations. I am unable to understand or communicate most health care concepts. Fair: I speak and understand well enough to have extended conversations about current events, work, family, or personal life. Native speakers notice many errors in my speech or my understanding. I have difficulty communicating about health care concepts. Good: I speak well enough to participate in most conversations. Native speakers notice some errors in my speech or my understanding, but my errors rarely cause misunderstanding. I have some difficulty communicating necessary health concepts. Advanced: I speak very accurately, and I understand other speakers very accurately. Native speakers have no problem understanding me, but they probably perceive that I am not a native speaker. Native/functionally native: I converse easily and accurately in all types of situations. Native speakers, including highly educated, may think that I am a native speaker, too.

Abbreviations: EM, emergency medicine; PGY, postgraduate year; SC, South Campus residency; UC, University Campus; ERAS ${ }^{\circledR}$, electronic residency application service.

encounters with UC residents, this number was too low from which to draw any statistically significant meaning.

Our curriculum requires trainees to continue using translator phones until they are certified as a Dual Role Interpreters. However, we could not monitor individual patient encounters. Resident physicians who are not yet certified, but who participate in the integrated medical Spanish curriculum, may feel overconfident and are attempting history and physical exams in Spanish rather than using the translator phones. Providers may also be using family members as translators in the clinical environment, which is no longer allowed.

Our results indicate that $\mathrm{SC}$ resident physicians spoke Spanish with $66 \%$ of their patients. Given that SC has only nine dual role certified resident interpreters, this number seems unusually high. Following this quality improvement project, residents were again reminded that they should perform history and physical exams in Spanish only if they have been certified as a dual role provider. It is unclear which method was used in the remaining $27 \%$ of cases - family members or a combination of information gathering. While Centers for Medicare \& Medicaid Services require that all health care providers who receive federal funding provide trained interpreters in health care settings for patients with LEP, ${ }^{18}$ federal law does not mandate whether this service is via a live, contracted interpreter, web-based video interpreting service or two-way telephone interpreter, but does not permit the interpreter to be a family member.

Our secondary goals were to raise cultural awareness, train cultural competency, and increase professional preparedness and comfort level in this setting. Although this was incorporated into our curriculum and didactics, we did not individually measure this. We had anticipated seeing a difference in patient satisfaction given the additional cultural competency training.

The experimental nature of the linguistic and crosscultural curriculum needs to be refined for future studies. Resident physicians report baseline language fluency on residency applications (Table 3). Initial placement into the basic and advanced learning groups was via self-selection and interactions with the instructors at a medical Spanish boot camp at the beginning of internship, rather than by individual proficiency testing. Given busy schedules, our proficiency assessments also did not occur exactly at each 6-month mark.

\section{Conclusion}

Preliminary data suggest that incorporating Spanish language and cultural competency into residency training has an overall beneficial effect on patient satisfaction and adherence to medical recommendations in Spanish-speaking patients with LEP. It increases the chance that resident physicians will speak to patients in Spanish. Patients are also more likely to rate the Spanish used by trained resident physicians and the subsequent care provided as very good.

\section{Acknowledgments}

The authors would like to thank the Arizona Emergency Medicine Research Center (AEMRC), the Research Associates Program (RAP), and the medical student Michael Wyman for data collection, patient follow-up phone calls, and project support. 


\section{Disclosure}

The authors report no conflicts of interest in this work.

\section{References}

1. New Census Bureau Interactive Map Shows Languages Spoken in America; Release Number: CB13-143. Available from http://www.census.gov/ newsroom/press-releases/2013/cb13-143.html. Accessed August 8, 2013.

2. Shin HB, Kominski RA. Language Use in the United States. U.S. Census Bureau - American Community Survey Reports ACS-12. Available from: http://www.census.gov/prod/2010pubs/acs-12.pdf. Accessed April 01, 2013.

3. Betancourt JR, Renfrew MA, Green AR, Lopen L, Wasserman M. Improving Patient Safety Systems for Patients with Limited English Proficiency: A Guide for Hospitals. Rockville, MD, USA: Agency for Healthcare Research and Quality (AHRQ); 2007.

4. Schyve PM. Language differences as a barrier to quality and safety in health care: the Joint Commission perspective. J Gen Intern Med. 2007;22(Suppl 2):360-361.

5. Crane JA. Patient comprehension of doctor-patient communication on discharge from the emergency department. JEmerg Med. 1997;15(1):1-7.

6. Karliner LS, Jacobs EA, Chen AH, Mutha S. Do professional interpreters improve clinical care for patients with limited English proficiency? A systematic review of the literature. Health Serv Res. 2007;42(2): 727-754.

7. Information about providing language access services; National Council on Interpreting in Health Care. Available from http://www.ncihc.org/ faqs-for-healthcare-professionals. Accessed July 18, 2016.

8. Sampson A. Language Services Resource Guide for Health Care Providers. Los Angeles, CA, Washington, DC, Chapel Hill, NC: The National Health Law Program and The National Council on Interpreting in Health Care; 2007:133-138, Appendix B
9. Brown LD, Cai TT, DasGupta A. Interval estimation for a binomial proportion. Stat Sci. 2001;16:101-133.

10. Hampers LC, Cha S, Gutglass DJ, Binns HJ, Krug SE. Language barriers and resource utilization in a pediatric emergency department. Pediatrics. 1999;103(6 Pt 1):1253-1256.

11. Jacobs E, Chen AH, Karliner LS, Agger-Gupta N, Mutha S. The need for more research on language barriers in health care: a proposed research agenda. Milbank $Q$. 2006;84(1):111-133.

12. Cheng EM, Chen A, Cunningham W. Primary language and receipt of recommended health care among Hispanics in the United States. JGen Intern Med. 2007;22(Suppl 2):283-288.

13. Lurie N, Zhan C, Sangl J, Bierman AS, Sekscenski ES. Variation in racial and ethnic differences in consumer assessments of health care. Am J Manag Care. 2003;9(7):502-509.

14. David RA, Rhee M. The impact of language as a barrier to effective health care in an underserved urban Hispanic community. Mt Sinai $J$ Med. 1998;65(5-6):393-397.

15. Morales LS, Cunningham WE, Brown JA, Liu H, Hays RD. Are Latinos less satisfied with communication by health care providers? J Gen Intern Med. 1999;14(7):409-417.

16. Hu DJ, Covell RM. Health care usage by Hispanic outpatients as function of primary language. West J Med. 1986;144(4):490-493.

17. Carrasquillo O, Orav EJ, Brennan TA, Burstin HR. Impact of language barriers on patient satisfaction in an emergency department. J Gen Intern Med. 1999;14(2):82-87.

18. Centers for Medicare and Medicaid Services. Strategic Language Access Plan (LAP) to Improve Access to CMS Federally Conducted Activities by Persons with Limited English Proficiency (LEP). Baltimore: Department of Health and Human Services; 2014. Available from: https://www.cms.gov/About-CMS/Agency-Information/OEOCRInfo/ Downloads/CMS-LAP-Updated-2014-508.pdf. Accessed January 22, 2015.
Advances in Medical Education and Practice

\section{Publish your work in this journal}

Advances in Medical Education and Practice is an international, peerreviewed, open access journal that aims to present and publish research on Medical Education covering medical, dental, nursing and allied health care professional education. The journal covers undergraduate education, postgraduate training and continuing medical education

\section{Dovepress}

including emerging trends and innovative models linking education, research, and health care services. The manuscript management system is completely online and includes a very quick and fair peer-review system. Visit http://www.dovepress.com/testimonials.php to read real quotes from published authors. 